\title{
Should conservation of biodiversity involve private land? A Q methodological study in Poland to assess stakeholders' attitude
}

\author{
Sristi Kamal • Malgorzata Grodzinska-Jurczak
}

Received: 4 March 2014/Revised: 3 June 2014/ Accepted: 20 June 2014/

Published online: 4 July 2014

(C) The Author(s) 2014. This article is published with open access at Springerlink.com

\begin{abstract}
Biodiversity conservation is gradually shifting its dependency on public protected areas to take a more holistic ecosystem and landscape approach that includes private lands in addition to public lands. However, effective practice of biodiversity conservation on private land also depends on landowners' attitude and their willingness to participate and cooperate. This study focuses on Poland where conservation on private land is a relatively new concept but it is slowly gaining recognition, especially after its accession into the European Union. It investigates and classifies the diverse attitudes among stakeholder groups in Poland toward biodiversity conservation on private land that are part of protected areas. Four primary stakeholder groups were considered: conservation and park authorities, local administrative officials, local conservation based NGOs and private landowners. The study was conducted across three sites that represented three different forms of protected areas in Poland: a national park, a landscape park and a Natura 2000 site. Q methodology, a research method from psychology and other social sciences, was used to classify human subjectivity in stakeholders' attitude in a more systematic manner. The analysis yielded three predominant factors which highlighted the diversity in attitudes among the stakeholder groups based on their knowledge, concerns and experience in the subject. Additionally, it underlined the common recognition among all stakeholder groups for better policy support, stronger collaboration among stakeholder and more financial or compensatory support for landowners to make private land conservation more feasible. Understanding the differences in attitudes will help bridge the gap between conservation priority and conservation opportunity - a current challenge in the field of biodiversity conservation.
\end{abstract}

Communicated by Stephen Garnett.

S. Kamal $(\bowtie) \cdot$ M. Grodzinska-Jurczak Institute of Environmental Sciences, Jagiellonian University, Gronostajowa 7, Krakow 30-387, Poland e-mail: sristi.kamal@uj.edu.pl

M. Grodzinska-Jurczak

e-mail: m.grodzinska-jurczak@uj.edu.pl 
Keywords Private protected areas · Conservation · Human subjectivity - Q methodology

\section{Introduction}

Role of private land in biodiversity conservation

In-situ biodiversity conservation has traditionally relied on protected areas for its sustenance and recovery, and historically such areas often consisted of public lands or community/private lands that were converted to public lands. However growing demographic pressures, including encroachment and land degradation, along with rapid urban development has limited the amount of public lands that can be set aside for biodiversity conservation (Alers et al. 2007; Joppa et al. 2008). Additionally, there is a growing recognition for a more holistic approach to conservation that looks beyond the conventional model of public protected areas (Figgis 2004). The new approach aims for a bioregional model that conserves landscapes irrespective of ownership (Kamal et al. 2014a). This has led conservationists to explore other potential options, private land conservation being one of them.

(Kamal et al. 2014a) defines conservation on private land as land under private ownership of individuals, families or other non-public entities within an administrative protected area, or otherwise informally reserved or managed for nature conservation purposes. Within the limitations of its regional and historical context, private land can make significant contribution to increasing habitat for protected species, and to maintain connectivity (Smith et al. 2006; Tryjanowski et al. 2011). Mixed models of protected areas (a combination of both private and public lands) have always existed throughout history, as it is near impossible to have large track of contiguous landscapes or ecosystem without including some portion of private land in it. Additionally, conserving private land that are outside of formal protected areas are also being explored, examples of which include land under conservation easements, private reserves, conservation contracts and other similar tools (Doremus 2003; Fishburn et al. 2009; George 2002; Krug 2001; Langholz and Lassoie 2001; The Nature Conservancy 2013). In the long history of biodiversity conservation, private land conservation has been a fairly recent strategy but it is gaining momentum through the use of some innovative tools, especially in countries such as the USA, UK, Australia and some countries in Latin America and Africa (Environmental Law Institute 2003; Figgis et al. 2005; Leva 2002; Land Trust Alliance 2013).

\section{Conservation on private land in Poland}

Despite the growing recognition for the importance of private land in biodiversity conservation, conflict over conservation on private land still continues (Knight et al. 2006; Tikka and Kauppi 2003). Earlier challenges of displacement and relocation of people from protected areas has combined, and in some cases yielded to, concerns over property rights and the opportunity cost of conservation (Mascia 2003; Paloniemi and Tikka 2008). Since private land conservation lacks a cohesive approach at a global scale, it is difficult to assess the conservation impact as well as management challenges at a broader scale (Kamal et al. $2014 a, b)$. In its current state of organization and information availability, understanding the importance and impact of private land on biodiversity conservation is dependent on individual study sites/regions (Tryjanowski et al. 2014). 
This research focuses on Poland as its study site. Conservation on private land poses a unique challenge as well as opportunity in Poland, especially when we take into account its political history as well as its current status as a member of the European Union (EU) (Grodzinska-Jurczak et al. 2012). On one hand, private property is of special significance here because of its troubled past under communism when owning private property was not encouraged. On the other hand, Poland's progressive future requires adaptation to regional policies which will impact how people use their land now. Although private lands have traditionally been part of protected areas such as national parks, their cumulative proportion (about 10-12\%) has been significantly lower than that of public lands (Central Statistical Office Poland 2012). However, this proportion changed as Poland strived to become a part of the EU. In order to become a Member State of the EU, Poland had to adopt several EU policies into its national strategy, Natura 2000 being one of them. Simply put, Natura 2000 is a combination of two EU directives known as the Birds Directive (1979) and the Habitats Directive (1992) and together they form the cornerstone of EU's nature conservation strategy (European Commission 2013). They identify and protect important bird species and habitats of conservation value mentioned in their annexes. To meet the EU requirements, Poland adopted Natura 2000 and designated sites all across the country, covering nearly $20 \%$ of Poland's territory. Natura 2000 overlaps with almost all previously designated protected areas, in addition to incorporating new sites (Central Statistical Office Poland 2012). Considerable proportion of Natura 2000 also lies on private land and in some cases it covers entire municipalities (Grodzinska-Jurczak et al. 2012; Grodzinska-Jurczak and Cent 2010). This brings private land to the forefront of protected areas and biodiversity conservation in Poland.

However, conservation on private land in Poland has faced its fair share of protests right from its inception. For instance, the site designation process of Natura 2000, which was hastened to meet the EU requirements, was based on pure ecological criteria to determine the conservation priority of the land (Cent et al. 2007; Grodzinska-Jurczak and Cent 2011). This resulted in considerable amount of conflict among conservation authorities, municipalities and landowners (Grodzinska-Jurczak et al. 2012). National parks and other protected areas which contained private land within their boundaries are now part of Natura 2000 as well. The next phase, the development of management plan for each site, is currently underway and this phase has also been conflict-ridden. Thus, it becomes imperative to understand stakeholders' attitude toward private land conservation in order to mitigate such conflicts and make conservation more effective. Better understanding of stakeholders' attitudes would help overlay conservation priority as identified by the conservation policies such as Natura 2000 on conservation opportunity, indicated by stakeholders' willingness and capacity to participate.

Therefore, our research goal is to investigate and characterize the attitudes among different stakeholder groups toward the feasibility of biodiversity conservation on private land in Poland. To do this, the study used a methodology that helps quantify human subjectivity known as Q methodology. This study will help combine the knowledge on conservation priority with that of conservation opportunity as described by Knight and Cowling (2007) and Knight et al. (2010). It will also equip conservation authorities with information that could help to address the concerns of landowners and local authorities.

\section{Q methodology}

Q methodology was first developed by psychologist/physicist William Stephenson in the 1930 s, with the goal of revealing human subjectivity in attitudes in a more objective 
manner (Brown 1980; Cross 2005; Kamal et al. 2014b). It collects and analyses data in a way that allows for statistically sound results while leaving scope for qualitative, in-depth interpretation of the results (Brown 1996). It is important to note that unlike other quantitative methodologies, Q methodology requires relatively small sample of respondents. This is because the goal of conducting a $\mathrm{Q}$ study is to focus on what the different views are, and not how many people are expressing it (Brown 1996; Watts and Stenner 2005). Therefore, it describes a population of viewpoints and not a population of people expressing those views (Van Exel and De Graaf 2005; Risdon et al. 2003). Although it was initially developed as a tool for psychological research, Q methodology has found its application in various fields of social sciences, education, health care and medicine (Brown 1996; Deignan 2009; Spurgeon et al. 2012; Webler et al. 2009).

A detailed description of $\mathrm{Q}$ methodology and its principles have already been covered by Brown (1980), Watts and Stenner (2012), Kamal et al. ( 2014b) and (Van Exel and De Graaf 2005) to name a few, and so we consider it to be outside the goal and scope of this paper. Nevertheless, we present a short summary as its use in socio-ecological research so far has been fairly limited. Q methodology allows for a sample of statements known as the $\mathrm{Q}$ set (that respond to only one particular question) to be arranged in a pre-described quasi normal distribution based on their importance to the respondent. The number of statements in a $\mathrm{Q}$ set depends on the aim of the research, the number of dimensions (of the research subject) to be explored and the target respondents, but it usually ranges between 30 and 60 (Logo 2013; Watts and Stenner 2005). The statements are sorted using a pre-defined scale. There are fixed number of slots assigned to each level on the scale - it has the least number of slots at the extremes and the highest in the center creating an inverted pyramid. Hence, it somehow directs the respondents to put the statements in a quasi-normal distribution, whose size is defined by the researcher. As an example, the structure of the inverted pyramid used in this study has been presented in Fig. 1.

Q methodology uses a negative-positive continuum scale instead of a positive continuum only. This is done for several reasons. It impresses upon the respondents that some of the statements are meant to be negative for them, while others are positive or neutral. It also makes the limitation at each level of the scale apparent to the respondent and the analysis more convenient for the researcher. Each respondent ranks all the statements based on his/her preference and a completed response from a respondent is referred to as a Q sort. After a Q sort is collected, a short interview is conducted with each respondent to get his/her feedback as well as get an additional insight into the respondent's perspective which could help in the final interpretation of the results.

The Q sorts collected from all respondents undergo an inverted factor analysis (usually in PQ Method, PCQ or similar software specific for Q methodology). It is an inversion of the conventional factor analysis (or $\mathrm{R}$ analysis) in that $\mathrm{Q}$ methodology correlates the $\mathrm{Q}$ sorts (or the people) rather than the statements - the Q sorts are the dependent variables and the statements are the independent variables (Brown 1980; Watts and Stenner 2005). The output from a Q methodology reduces the individual opinions into factors based on their similarities and differences. Thus, each factor is a group of similar opinions and people loading high on this factor are assumed to think in a similar way, with respect to the subject in question.

Each factor in a Q methodology output is then open for interpretation, which is done by the researcher. This is a multi-step process that considers all the output data generated from the analysis. Watts and Stenner (2012) presents a detailed step-by-step guide to interpret results from a Q methodology analysis. 


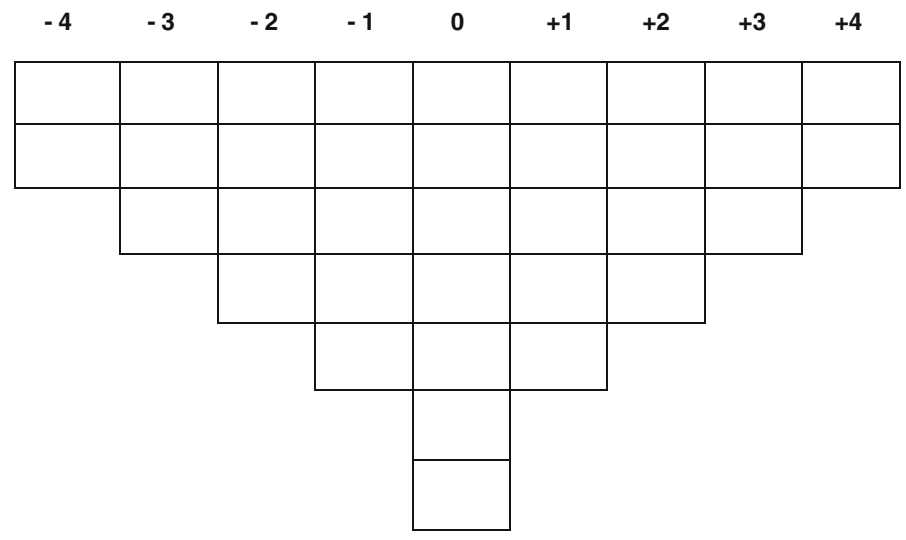

Fig. 1 Q sort template with fixed number of slots (for statement numbers) at each level of the positivenegative continuum scale

\section{Research methodology}

Sample sites and sample respondents

The sites in Poland were chosen based on the data available from the Central Statistical Office of Poland's annual report (2012). The criteria for choosing sample sites were:

- Cover three most prominent forms of protected areas in Poland: a national park, a landscape park and a Natura 2000 site were selected.

- Total size of the protected area: the minimum size of a protected area that was considered as a sample site was 15,000 hectares. This was done to ensure a reasonable size of protected area with a considerable overlap with human habitation.

- Percentage of private land inside of the protected area: For national parks, which are generally more exclusive and with limited human habitation, the minimum level was set at $15 \%$. Also, percentage of arable land (min. $10 \%$ ) was taken into account. For landscape parks and Natura 2000 sites, data on the percentage of private land within a park boundary was not available. Instead, the percentage of arable land was taken as an indicator of agricultural and private land. The minimum percentage of arable land for both forms of protected areas was set at $50 \%$.

- Minimum overlap with other forms of protected areas: Almost all protected areas in Poland, especially national parks, are also Natura 2000 sites. Hence, those landscape parks and national parks with minimum overlap of Natura 2000 (less than $15 \%$ of the total protected area) were prioritized. For the Natura 2000 site, those that were only under Natura 2000 and no other forms of protection were considered.

Based on these four criteria, Biebrzanski National Park in north-east Poland (Podlaskie voivodship/state), Skierbieszowski Landscape Park in south-east Poland (Lubelskie voivodship/state) and Dolina Gornej Wisly Natura 2000 site in southern Poland (Slaskie voivodship/state) were selected as the three study sites.

From each site ten respondents were selected (30 respondents in total). To shortlist the respondents, the stakeholder groups of interest were first identified and this process was guided by the goal to capture as much diversity in perspectives as possible. The main 
stakeholder groups included in this study were the protected area managers or conservation authorities, the local level administrative authorities within the park boundary, conservation based NGOs, and landowners/farmers. Each protected area was managed by two conservation agencies (for instance, Biebrzanski National Park had the national park agency as well as the Natura 2000 implementation agency; the Natura 2000 site had its own agency and an additional site management authority), so representative from both the conservation agencies were included in the study. Selection of respondents from the conservation agencies, protected area managers and the local administrative authorities was through judgment sampling and the chief administrator/director from each office was contacted (Marshall 1996). To select NGOs, a list of conservation oriented NGOs working around each protected area was prepared and an NGO was chosen at random. Within each organization, the coordinator of community based conservation programs was selected. In the case of landowners, a list of local village heads and community contacts for implementation of agricultural programs were provided by each of the county/municipal office. From each list six respondents were chosen at random, a total of 18 respondents.

Data collection and analysis

The statements for conducting the Q methodology study were prepared after an exhaustive literature review on the topic of private land conservation. This included research and review articles published in peer reviewed journals, articles and opinions published in newspapers (national and international) and other popular media such as internet and television. The statements were themed to cover three dimensions of private land conservation: its importance (or the lack of it), the main challenges (economic, social, cultural, political) and the possible solutions. Initially, 45 statements were prepared and they were subjected to a pilot test with ten respondents. Based on the feedback and the results, the statements were restructured and reduced in number to 35 (to avoid overlap and confusion).

Once the statements and the list of respondents were finalized, data was collected through a face-to-face interaction where the purpose of the research and the rules of the exercise were explained in detail. Each statement was presented as a single piece of paper and the respondent was asked to arrange them on a predefined scale ranging from -4 to +4 . The interviewer also had a detailed discussion with the respondent to gather his/her final thoughts, feedback on the exercise, as well as to note any additional information that the respondent wished to provide.

Of the data from 30 respondents, 28 were used for the analysis as two of the Q sorts had errors in them (such as double entry of a statement number) and had to be rejected. $57 \%$ of the final respondents were male $(n=16)$ and $43 \%$ were female $(n=12)$.

\section{Results}

Factor extraction

The Q sorts were subjected to factor analysis using the PQ method software that is available for free download from the internet. Brown (1980), Watts and Stenner (2005) and Watts and Stenner (2012) were consulted during the analysis. The factors were extracted using centroid analysis (Horst's centroid). The data generated eight factors of which the first three were selected for the analysis due to the following reasons: first, it is a standard 
procedure to consider factors with Eigen values greater than 1 and having at least two respondents (that is, have at least two defining Q sorts) load on the factor (Brown 1980; Watts and Stenner 2012). Second, together the three factors explained $51 \%$ of the total variance and had minimal correlation within them, whereas the latter factors had stronger correlation with the first three factors as well as with one another. Finally, the difference in error in residual variance did not change significantly when considering four factors versus three factors. Each factor had a few Q sorts that especially contributed to defining that particular factor. The respondents corresponding to these defining Q sorts for each factor have been mentioned in the following section on factor interpretation.

The three chosen factors were then subjected to varimax rotation before the software conducted the final analysis. The three factors together had 26 defining Q sorts (two Q sorts loaded individually on two other factors that did not meet the criteria of selecting a factor). The software also presented the factor array table (or a model Q sort). A factor array table contains the statement scores for each factor based on the weighted average of its defining $\mathrm{Q}$ sorts (Table 1). Simply put, a factor array represents the statement scores on a factor that a Q sort would assign if it were to load a hundred percent on that factor. The statement scores in this table were used in the final interpretation. Taking a conservative approach, distinguishing statements (that is, statements which were highlighted in the analysis as being significant to the interpretation of a particular factor) at $p<0.01$ were also used in the interpretation, even though they might have had lower statement scores. Following the same logic, consensus statements (that is, statements that did not help in distinguishing among the three factors) at $p<0.01$ were excluded from the interpretation of individual factors, even though some of them had higher statement score. However, the consensus statements were interpreted together to highlight the issues on which each group of attitude (that is, all stakeholders) seem to agree/disagree on.

Consensus statements: These are statements that generated a common agreement (or disagreement) and therefore didn't contribute to distinguishing among the factors. However, it is important to highlight them because they represent the common attitude that was identified among all stakeholders. People loading on each group of attitude (or each factor) seem to have a common consensus on the fact that private land as part of protected areas should consider landowners' willingness to participate (statement 2), which has not been the case in Poland. So far, it has been a EU/national prescription that did not take landowner's consent into account and, as such, is not working well in Poland due to lack of appropriate policy, and lack of support for landowners from the responsible authorities (statements 24, 28 and 20). Instead of being a broad prescription that one is forced to implement, conservation on private land would be more effective if it can demonstrate through peer experience that there are real, tangible benefits from private land conservation (statement 33).

\section{Factor interpretation}

A factor summary with its defining Q sorts (that is, respondents who loaded significantly on that factor) has been presented in Table 2. The interpretations of the three factors have been presented after the table. In each factor interpretation, the first number in the parenthesis is the statement number and its adjacent number is the score allotted to that statement for the particular factor. 


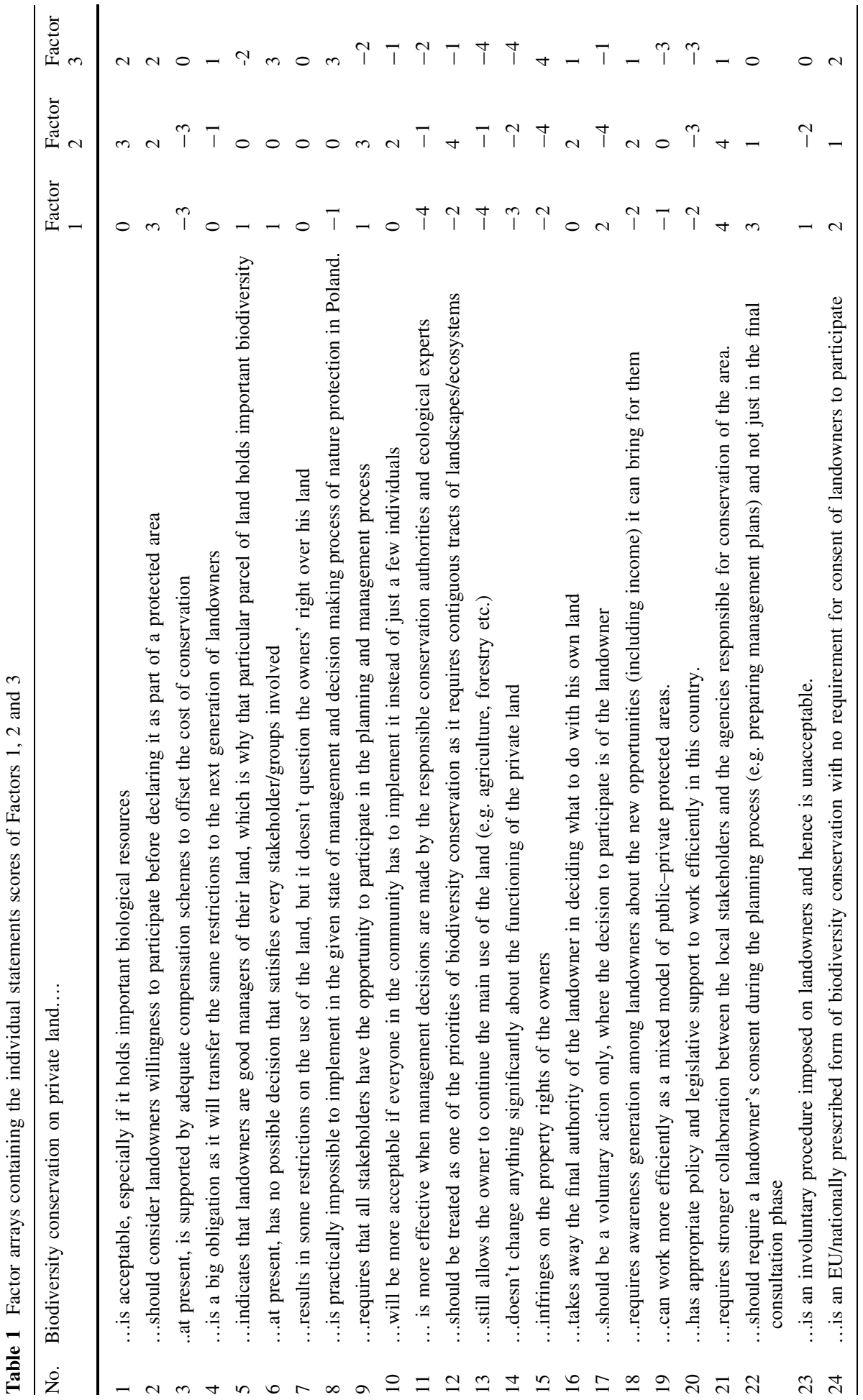




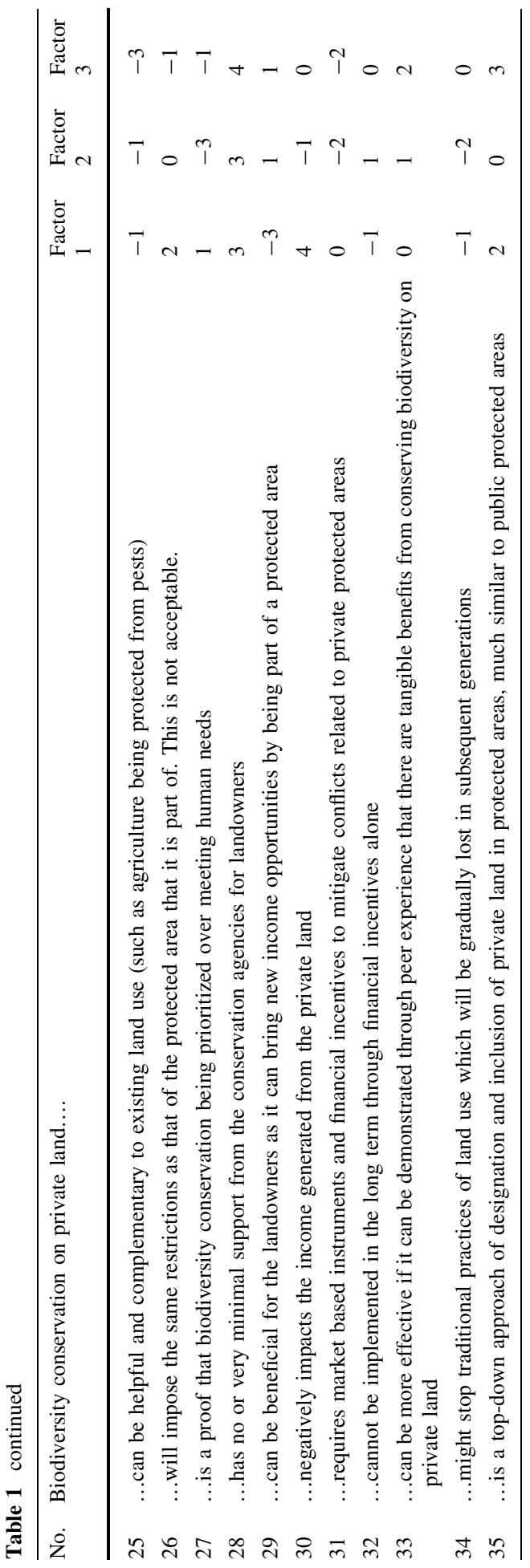




\section{Factor 1}

Factor summary: Factor 1 explains $30 \%$ of the total variance and has an Eigen value of 8.35. Twelve respondents loaded significantly on this factor, of which seven were male and five were female. Eight respondents were from the national park site, two from the Natura 2000 site and two from the landscape park. Except for the administrator from the municipality office that is part of the national park, the eleven remaining respondents were landowners (including all landowners from the national park site). Of the eleven landowners, nine were also farmers.

Interpretation of Factor 1: The Skeptic-biodiversity conservation on private land is at a cost that landowners have to bear

Including private land in biodiversity conservation strategy is a proof that conserving nature is being prioritized over human needs and therefore has no outcome that can satisfy all stakeholder groups $(27:+1 ; 6:+1)$. So far, it has been a top-down approach where the inclusion of private land in protected areas and the subsequent restrictions have been imposed in a manner similar to public protected areas $(35:+2 ; 26:+2)$. Once a part of a protected area, a landowner is unable to use his land the way he has always used it (13:-4). Such an involuntary and imposed form of biodiversity conservation is unacceptable $(23:+1)$. Although it might not infringe on the property rights of a landowner directly, conservation on private land will significantly change how the land functions for the landowner $(15:-2 ; 14:-3)$. It negatively impacts the income generated from the land without bringing in new economic opportunities $(30:+4 ; 29:-3)$. There is also a lack of adequate compensatory support such as compensation schemes to offset the cost of becoming a private protected area and bearing the restrictions (3:-3). Additionally, conservation strategies do not complement or benefit the existing land use in any way that is useful for the landowner (25:-1). If a parcel of land has been identified as having conservation value, it only implies that the landowner has been a good manager of his land $(5:+1)$. Hence, even though private lands may sometimes hold important biological resources, it should not be treated as a priority in large scale nature conservation strategies as landowners are inherently good caretakers $(1: 0 ; 12:-2)$.

Private land as a conservation strategy will work only when it is voluntary $(17:+2)$. Also, the management and the decision making process needs to be more inclusive: managing authorities or ecological experts should not be the only group with the decision making power over a private or mixed model of protected area $(11:-4)$. There needs to be a stronger collaboration between the local stakeholder groups and the authorities in both the planning and implementation phase, and not as a final consultation with local communities on pre-decided plans $(21:+4,22:+3)$. Lastly, support structures such as financial compensation and market based incentive programs are important and should be in place to complement such conservation strategies right from the start $(32:-1 ; 31: 0)$.

\section{Factor 2}

Factor summary: Factor 2 explains $14 \%$ of the total variance and has an Eigen value of 3.82. Nine respondents loaded significantly on this factor, of which five were male and four were female. Four respondents were from the Natura 2000 site, three from the landscape park and two from the national park site. This factor was loaded entirely by all protected area management authorities, NGOs representatives and municipality administrators (except one from the national park) from all three sites. No landowner/farmer loaded on this factor. 


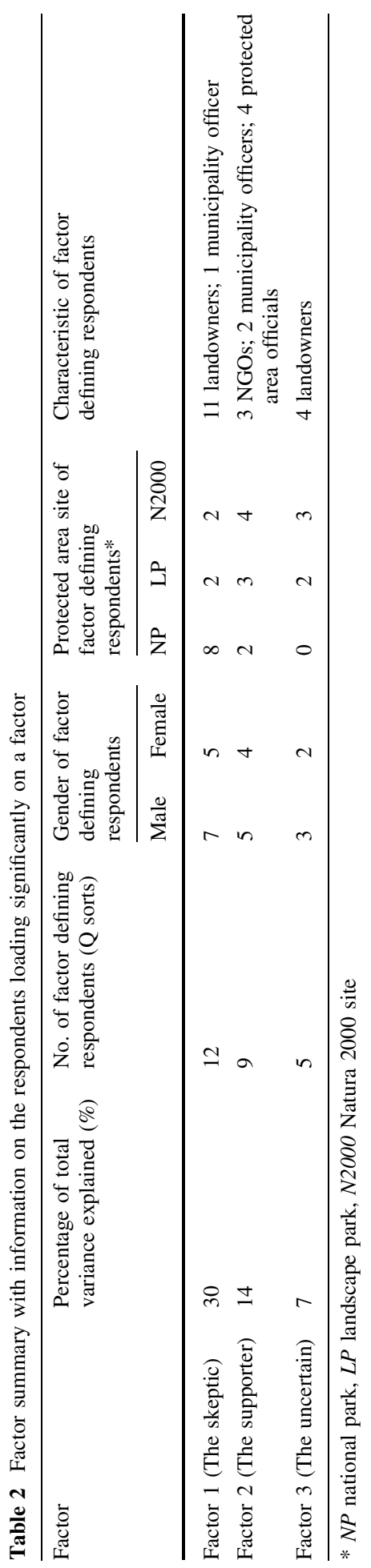


Interpretation of factor 2: The Supporter-Private land is important to biodiversity conservation

Private land should be treated as a priority in nature conservation strategies as they are crucial in conserving larger ecosystems and landscapes as a whole $(12:+4)$. It is not the objective of private land conservation to undermine human needs and nor is it about restricting people's right over their land in perpetuity $(27:-3 ; 4:-1)$; rather, it is based on the simple fact that private land often holds important biological resources and therefore, needs to be conserved $(1:+3)$. People are generally good managers of their own land (which has sustained the important biodiversity on private land so far), but that should not be used as a pretext to make it a pure voluntary strategy and rely solely on a landowner's willingness to participate or not $(5: 0 ; 17:-4 ; 23:-2)$. Private land conservation does not harm a landowner as it doesn't infringe on his property rights nor does it impact the income generation from the land $(15:-4 ; 30:-1)$. Although it might not directly benefit the current land use and might even modify it, private land conservation has the potential to bring in new economic opportunities $(13:-1 ; 25:-1 ; 29:+1)$. The primary challenges in promoting conservation on private land has been to negate the sense among landowners that their decision making power and authority over their land is being taken away, and to make them aware of the potential economic opportunities $(16:+2 ; 18:+2)$. These two factors, along with the lack of adequate compensation schemes for landowners to offset the opportunity costs of conservation, have made private land conservation a challenge in Poland (3:-3).

If private land is to be conserved on its own or in a mixed model of protected areas then the decision making process will need to be more inclusive and not limited to managing authorities alone $(19: 0 ; 11:-1)$. The top-down mechanism of decision making needs to make way for a more open process where all stakeholders groups have an equal opportunity to participate in the planning and management of such areas $(35: 0 ; 9:+3)$. Finally, peer pressure can be more effective than prescription, and it will be easier to convince landowners of conserving their land when they witness others in their communities do so $(10:+2)$.

\section{Factor 3}

Factor summary: Factor 3 explains $7 \%$ of the total variance and has an Eigen value of 1.98. Five respondents loaded on the factor, of which three were male and two were female. Three respondents were from the Natura 2000 site and two from the landscape park. No respondent from the national park loaded on this factor. All five respondents were landowners and farmers.

Interpretation of factor 3: The Uncertain-Private land can conserve biodiversity but can threaten landowners' rights in the process

Private land conservation, in its current state, doesn't have any solution that will satisfy the interest of all stakeholders $(6:+3)$. On the one hand, it is important to conserve private land, especially if it holds important biological resources $(1:+2)$. In such cases, it is not a choice between nature and human needs, and conservation shouldn't have to depend only on voluntary actions and a landowner's managing capabilities $(27:-1 ; 17:-1: 5:-2)$. On the other hand, conservation on private land threatens to infringe on a landowner's property rights and change the primary functioning of his land significantly $(15:+4 ; 14:-4)$. It does not allow for the landowner to continue the use of his land as he used to and even if it did, conservation measures do not benefit or complement his land use in any way (13:-4; 25 :3 ). Moreover, the restrictions of being part of a protected area will often be in perpetuity 
and therefore a burden inherited by next generation of landowners $(4:+1)$. Along with lack of compensatory schemes, the top-down approach of site selection and designating private land as part of protected areas, has also made it conflict ridden $(3: 0 ; 35:+3)$. Even as a mixed model of public and private protected areas, it will not work efficiently as it will impose the same restrictions on the private property as that of the public protected area it is a part of $(19:-3 ; 26:-1)$. Thus, private land conservation comes across as a tool that takes away a landowner's authority over his own land $(16:+1)$.

Considering the current state of management structure and process in Poland, it is almost impossible to have effective private land conservation $(8:+3)$. Decision making power should not lie in the hands of the managing authorities only and there is a need for stronger collaboration among local stakeholder groups and the managing authorities. (11:$2 ; 21:+1)$. There might be new income opportunities from private protected areas that can mitigate some of the challenges, but landowners need to be made aware of those potential opportunities $(18:+1 ; 29:+1)$.

\section{Discussion and conclusion}

This study uses a very specific social sciences methodology (Q methodology) to address an important research question for biodiversity conservation in Poland. Socio-ecological researches, especially related to investigating human attitudes, have been at a disadvantage because of its often subjective nature but tools such as $\mathrm{Q}$ methodology provide a unique opportunity that allows for quantifying human subjectivity. Therefore, use of such methodologies should not be dictated by a discipline and instead, should be determined by the research question to be addressed. However, it is important to remember that while Q methodology is very useful to explore and classify the attitudes based on their similarities and differences, but its findings cannot be extrapolated to the whole population.

Three primary attitudes emerged, two of which were loaded almost completely by landowners and this reflects the diversity in attitudes on the subject even within the same stakeholder group. Therefore, it would be shortsighted to assume that all landowners have the same attitude toward biodiversity conservation on private land. Even though both the "Skeptic" and the "Uncertain" were loaded by landowners, the latter is relatively more inclined toward biodiversity conservation. If conservation priority was to overlap with conservation opportunity, then for two parcels of land with equal conservation priority, the one with the "Uncertain" holds a higher conservation opportunity than the one owned by the "Skeptic".

"Skeptics" are predominantly against private land conservation, mostly due to the fear of economic losses that they might have to bear. This fear stems from two reasons: first, the lack of actual financial incentives for private land conservation in Poland and second, the lack of communication and information dissemination on what conservation on private land entails. Financial incentives for conservation on private land in Poland is mostly limited to agricultural land only, the most popular program being the EU Agri-Environment scheme which neither targets all land uses and nor does it focus on private land within protected areas. Without proper financial support mechanisms and tangible benefits, it would be difficult to covert a "Skeptic" into even an "Uncertain". Also, the interviews conducted after each Q sort highlighted the need for a more accessible form of information dissemination at the community level to generate awareness on what conservation strategies such as Natura 2000 on private land actually entail. Most landowners were unaware 
or misinformed about regulations on private land within the boundaries of different types of protected areas.

Scanning across all the stakeholder groups included in this study, we find a distinct dichotomy in the perception of the importance of private land conservation, with NGOs, government institutions and park officials at one end of the spectrum and the landowners at the other. This result may not be surprising, but it is yet another evidence of lack of good governance in protected area management. The dichotomy can be related to characteristics that define the standpoint of each stakeholder group. Analyzing the standpoint of one end of the spectrum, we find that the views stated by NGO employees, park and municipal employees on the importance on private land conservation are in harmony with the working principles of their organizations and their attitudes are also a reflection of their beliefs and their loyalty to the visions of the organizations they work for (the "Supporter"). However, as the managers of such protected areas, they have not been able to transfer their vision and understanding of the importance of private land conservation to their communities, which is why the "Supporter" also wishes for more collaboration and a participatory approach to decision making.

Focusing on the other end of the spectrum, most landowners are in direct contact with their land and the resources it supports. They bear strong ties to their land and both the "Skeptic" and the "Uncertain" stated themselves to be good stewards of the land they manage. When management of private protected areas is done in a top-down manner as has been the case in Poland, then it is often viewed as questioning a landowner's capability to manage his land. Another key factor defining the "Uncertain's" standpoint on this subject is the issue of property rights, and any interference in what a landowner believes to be his right can be viewed as a threat. This, together with the hierarchical relationships among the stakeholder groups has created a sense of distrust toward any authoritative figure/institution (for both the "Skeptic" and the "Uncertain"). Economic incentives are influential in private land conservation but they should not be considered as the only driving force that maneuvers landowners' attitude and this fact must be weighed while developing strategies that will affect their authority over their land. Despite the obvious differences in the three attitudes groups, they agree on a few issues. The common thinking thus far has been that private land conservation is a top down national or regional policy directly prescribed without taking local context into account and everyone, including local authorities feels wronged in the process. All stakeholder groups, including local conservation authorities and government administration, acknowledge the importance of landowners' willingness to participate, and yet the management authorities of protected areas have not been able to realize landowners' participation as something more than just a formal requirement. Each group of attitude emphasized on the need for stronger collaboration, which is an encouraging sign in that every stakeholder group recognizes its importance and express their willingness to strive for it. However, there needs to be more room in the national and regional policies to adapt to local context and create a platform for stronger collaboration among stakeholder groups.

Private land conservation has a long way to go in Poland before its potential in biodiversity conservation is fully realized. Unless the challenges highlighted through the findings of this study are addressed and the opportunities capitalized, private land in biodiversity conservation will remain controversial and conflict ridden. The results from this study not only help understand the different attitudes that exist among stakeholders, but it also gives rise to more research questions such as the possible relationship between the expressed attitude of landowners and their socio-demographic characteristics. Such 
information is also crucial to designing policies as well as to mitigate conflict that revolves around biodiversity conservation on private land in Poland.

Acknowledgments The study described here was done as a part of the following Jagiellonian University Grants: Information, education and communication for the natural environment (WRBW/DS/INoS/760), and Investigating challenges and opportunities in promoting biodiversity conservation on private land (DS/ MND/WBiNoZ/INoS/16/2013). The authors would also like to express their gratitude to Dr Marcin Kocor (Institute of Sociology, Jagiellonian University, Krakow, Poland) for the technical advice and guidance he provided throughout this study.

Open Access This article is distributed under the terms of the Creative Commons Attribution License which permits any use, distribution, and reproduction in any medium, provided the original author(s) and the source are credited.

\section{References}

Alers M, Bovarnick A, Boyle T, Mackinnon K, Sobrevila C (2007) Reducing threats to protected areas: lessons from the field. IOP World Bank and UNDP. http://siteresources.worldbank.org/ INTBIODIVERSITY/Resources/ReducingThreats-web.pdf. Accessed 14 Dec 2013

Brown SR (1980) Political subjectivity: Applications of Q methodology in political science. Yale University Press, New Haven

Brown SR (1996) Q methodology and qualitative research. Health Res 6(4):561-567

Cent J, Kobierska H, Grodzińska-Jurczak M, Bell S (2007) Who is responsible for Natura 2000 in Poland? a potential role of NGOs in establishing the programme. Int J Environ Sustain Dev 6:422-435

Central Statistical Office Poland (2012) Chapter 1: Environment and environmental protection. In Concise statistical yearbook of, Poland, pp 25-62

Cross RM (2005) Exploring attitudes: the case for Q methodology. Health Educ Res 20(2):206-213

Deignan T (2009) Enquiry-based learning: perspectives on practice. Teach High Educ 14:13-28

Doremus H (2003) A policy portfolio approach to biodiversity protection on private lands. Environ Sci Policy 6:217-232

European Commission (2013) Natura 2000 network. IOP European Commission: Environment. http://ec. europa.eu/environment/nature/natura2000/. Accessed 20 Nov 2013

Environmental Law Institute (2003) Legal tools and incentives for private lands in Latin America: building models for success. Washington DC: Environmental Law Institute. https://cmsdata.iucn.org/ downloads/spn__legal_tools_and_incentives_for_private_lands_conservation.pdf. Accessed 11 Dec 2013

Figgis P (2004) Conservation on private lands: the Australian experience. IUCN, Gland and Cambridge, p i31

Figgis P, Humann D, Looker, M (2005) Conservation on private land in Australia. Parks: protected areas programme-Private Protected Areas 15(2):19-29

Fishburn IS, Kareiva P, Gaston KJ, Armsworth PR (2009) The growth of easements as a conservation tool. PLoS One. doi:10.1371/journal.pone.0004996

George S (2002) State Government incentives for habitat conservation-a status report. Defenders of wildlife, USA. http://www.defenders.org/resources/publications/programs_and_policy/biodiversity_ partners/conservation_in_america_state_profiles.pdf. Accessed 1 Dec 2013

Grodzińska-Jurczak M, Cent J (2010) Udział społeczny szansą dla realizacji programu Natura 2000 w Polsce. Public participatory approach—a chance for Natura 2000 implementation in Poland. Chrońmy Przyrodę Ojczystą 66(5):341-352

Grodzińska-Jurczak M, Cent J (2011) Expansion of nature conservation areas: problems with Natura 2000 implementation in Poland? Environ Manag 47:11-27

Grodzinska-Jurczak M, Strzelecka M, Kamal S, Gutowska J (2012) Effectiveness of nature conservation-a case of Natura 2000 sites in Poland. In: Sladonja B (ed) Protected area management. In Tech, Rijeka, pp 183-202

Joppa LN, Loarla SR, Pimm SL (2008) On the protection of protected areas. PNAS 105(18):6673-6678

Kamal S, Grodzinska-Jurczak M, Brown G (2014a) Conservation on private land: a review of global strategies with a proposed classification system. J Environ Plan Manag. doi:10.1080/09640568.2013. 875463 
Kamal S, Kocor M, Grodzinska-Jurczak M (2014 b) Quantifying human subjectivity: when quality meets quantity. Qual Sociol Rev 10(3) (In press)

Knight AT, Cowling RM, Campbell BM (2006) An operational model for implementing conservation action. Conserv Biol 20(2):408-419

Knight AT, Cowling RM (2007) Embracing opportunism in the selection of priority conservation areas. Conserv Biol 211:124-1126

Knight AT, Cowling RM, Difford M, Campbell BM (2010) Mapping human and social dimensions of conservation opportunity for the scheduling of conservation action on private land. Conserv Biol $24: 1348-1358$

Krug W (2001) Private supply of protected land in Southern Africa: A review of markets, approaches, barriers and issues. World Bank/OECD international workshop on market creation for biodiversity products and services. http://earthmind.net/values/docs/private-protected-land-southern-africa.pdf. Accessed 17 Dec 2013

Land Trust Alliance (2013) Total acres conserved by local and national land trusts in 2010. IOP Land Trust Alliance http://www.landtrustalliance.org/land-trusts/land-trust-census/data-tables. Accessed $01 \mathrm{Dec}$ 2013

Langholz J, Lassoie J (2001) Perils and promise of privately owned protected areas. Bioscience 51(10):79-80

Leva CED (2002) The conservation of nature and natural resources through legal and market-based instruments. Rev Eur Community Int Environ Law 11(1):84-95

Logo E (2013) Q-Method based environmental awareness measurement in transportation. Int J Traffic Transp Eng 3(1):45-53

Mascia MB (2003) Conservation and the social science. Editorial. Conserv Biol 17(3):649-650

Marshall MN (1996) Sampling for qualitative research. Fam Pract 13(6):522-525

Paloniemi R, Tikka PM (2008) Ecological and social aspects of biodiversity conservation on private lands. Environ Sci Policy 11:336-346

Risdon A, Eccleston C, Crombez G, McCracken L (2003) How can we learn to live with pain? A Q methodological analysis of the diverse understandings of acceptance of chronic pain. Soc Sci Med 56:375-386

Spurgeon L, Humphreys G, James G, Sackley C (2012) A Q-methodology study of patients' subjective experiences of TIA. Stroke Res Treat 2012:1-10

Smith G, Phillips E, Doret G (2006) Biodiversity conservation on private land. In 42nd ISoCaRP council case studies, Sydney. http://www.isocarp.net/Data/case_studies/828.pdf. Accessed 10 Nov 2013

Tikka PM, Kauppi P (2003) Introduction to special issue: protecting nature on private lands - from conflict to agreements. Environ Sci Policy 6:193-194

The Nature Conservancy (2011) Private lands conservation. IOP The nature conservancy, USA. http://www. nature.org/about-us/private-lands-conservation/index.htm. Accessed 15 Nov 2013

Tryjanowski P, Sparks TH, Jerzak L, Rosin ZM, Skórka P (2014) A paradox for conservation: electricity pylons benefit avian diversity in intensively used farmland. Conserv Lett 7:34-40

Tryjanowski P, Hartel T, Báldi A, Szymański P, Tobolka M, Herzon I, Goławski A, Konvička M, Hromada M, Jerzak L, Kujawa K, Lenda M, Orłowski M, Panek M, Skórka P, Sparks TH, Tworek S, Wuczyński A, Żmihorski M (2011) Conservation of farmland birds faces different challenges in Western and Central-Eastern Europe. Acta Ornithol 46:1-12

Van Exel J, De Graaf G (2005) Q Methodology: a sneak preview. http://qmethod.org/articles/vanExel.pdf. Accessed 22 Oct 2013

Watts S, Stenner P (2005) The subjective experience of partnership love: a Q methodological study. Br J Soc Psycol 44:85-107

Watts S, Stenner P (2012) Doing Q methodological research. theory, method and interpretation. Sage, London

Webler T, Danielson S, Tuler S (2009) Using Q method to reveal social perspectives in environmental research. IOP Greenfield MA: Social and Environmental Research Institute http://www.seri-us.org/ sites/default/files/Qprimer.pdf. Accessed 25 Oct 2013 